\title{
Evaluation of spleen stiffness compared to liver stiffness as non-invasive predictors for esophageal varices in patient with liver cirrhosis (Egyptian study)
}

\author{
Amal Shawky¹, Ayman Abdel Aziz ${ }^{1}$, Christina Alphonse ${ }^{2}$ and Zakaria Mahmoud ${ }^{2 *}$ \\ ${ }^{1}$ Department of Gastroenterology, Ain Shams University Hospitals, El-Khalifa El-Maamoun, El-Qobba Bridge, Heliopolis, Cairo Governorate, Egypt \\ ${ }^{2}$ Theodor Bilharz Research Institute, Mahad Al Abhas Al Bahari, Warraq Al Arab, El Warraq, Giza Governorate, Egypt
}

\begin{abstract}
Introduction: Patients with liver cirrhosis have high incidence of oesophageal varices with high morbidity and mortality due to bleeding; active surveillance via upper gastrointestinal endoscopic examination may be unnecessary for patients, therefore, the increasing number of non-invasive predictors of oesophageal varices has gained wide attention. Nevertheless, few Meta analyses have involved predicting oesophageal varices using Liver Stiffness measured using fibroscan.
\end{abstract}

Aim of the work: To compare between predictive values of spleen stiffness and liver stiffness as non-invasive predictors of oesophageal varices in patients with liver cirrhosis.

Patients and methods: After taking consent, 61 patients with liver cirrhosis attending outpatient clinic at Theodor Biharz Research Institute were assessed by history taking, clinical examination, Complete blood count, serum alanine aminotransferase, serum aspartate aminotransferase, bilirubin, serum albumin, prothrombin concentration, Alpha fetoprotein, abdominal ultrasound, upper gastrointestinal endoscopy and fibroscan. Data was collected and analysed.

Results: This study included 61 patients with liver cirrhosis, 38 of them were males, with mean age $58.28 \pm 1.18$ years. All patients had post hepatitis C cirrhosis, and 6 of them had history of bilharziasis in addition.

Using U/S there were 12 patients $(19.67 \%)$ with mild ascites, 13 patients $(21.31 \%)$ with moderate ascites and 7 patients $(11.48 \%)$ with marked ascites 53 patients (86.90\%) had enlarged spleen, 8 patients (13.10\%) showed average spleen with Splenic longitudinal diameter mean (16.08 \pm 2.81$) \mathrm{cm}$ by U/S, 47 patients (77\%) had shrunken liver, 12 patients (19.7\%) showed average liver, 2 patients (3.30\%) had enlarged liver with portal vein diameter mean (13.70 \pm 2.26$)$ by U/S. Splenic stiffness mean was $(59.66 \pm 15.15) \mathrm{KPa} \&$ liver stiffness mean was $(29.46 \pm 12.11) \mathrm{KPa}$ by fibroscan.

Conclusion: Spleen stiffness is superior to Liver stiffness in predicting oesophageal varices in patients with liver cirrhosis and combination of spleen stiffness and liver stiffness is better than spleen stiffness and/or liver stiffness alone with sensitivity $95 \%$ and specificity $40 \%$.

\section{Introduction}

Acute variceal bleeding is the major cause (70\%) of upper gastrointestinal bleeding in cirrhotic patients with first episode mortality rate up to $15-20 \%$, The main predictors of bleeding in clinical practice are: large versus small varices, red wale marks, Child Pugh C versus Child Pugh A-B [1].

The gold standard for the diagnosis of oesophageal varices is EGD which must be performed at the time of cirrhosis diagnosis, in absence of varices at baseline endoscopy, EGD should be repeated every 2-3 years, whereas in patients with small varices, every $1-2$ years. In the setting of decompensation (large varices), EGD should be performed annually [2].

Endoscopy being invasive may be an unnecessary burden on some patients Therefore, predictors of bleeding should help to identify patients with the highest prevalence of oesophageal varices and improve the yield and cost-effectiveness of endoscopic screening [3].

Aim of the Work: To compare between predictive values of spleen stiffness and liver stiffness as non-invasive predictors of oesophageal varices in liver cirrhosis patients.

\section{Patient and methods}

\section{Patients}

This study was done on 61 patients diagnosed with liver cirrhosis based on history, clinical, laboratory and radiological data.

Excluding patients with history of upper GIT bleeding with endoscopic intervention, Hepatocellular carcinoma, Portal vein thrombosis, and those receiving medical treatment that decrease portal hypertension or directly acting antiviral drugs or patients with history of liver transplantation or Trans jugular intrahepatic Porto systemic shunt.

${ }^{\star}$ Correspondence to: Zakaria Mahmoud, Theodor Bilharz Research Institute, Mahad Al Abhas Al Bahari, Warraq Al Arab, El Warraq, Giza Governorate, Egypt, Tel: +20-235-401-019; E-mail: ibrahimshalash@yahoo.com

key words: oesophageal varices, liver, fibroscan, ultrasound

Received: December 05, 2019; Accepted: December 20, 2019; Published: December 23, 2019 


\section{Patients were classified into three Groups:}

- Group 1: included 20 patients with liver cirrhosis and small sized oesophageal varices.

- Group 2: included 21 patients with liver cirrhosis and medium or large sized oesophageal varices.

- Group 3: included 20 patients with liver cirrhosis without oesophageal varices.

\section{Methods}

After getting the ethical committee approval and a written consent from all patients, they underwent the following:

- Full history taking: with special emphasis on possible causes (bilharziasis, hepatitis B,C, etc....) and complications of liver cirrhosis ( jaundice, ascites, etc....)

- Clinical examination: with special stress on stigmata of liver cell failure and signs of portal hypertension (ascites, splenomegaly, etc....)

- Laboratory investigations including: Complete blood count, serum alanine aminotransferase, serum aspartate aminotransferase, total and direct bilirubin, serum albumin, prothrombin time and concentration, Alpha fetoprotein.

- Abdominal ultrasonography Using real time scanning device (Philips)

- Upper Gastrointestinal Endoscopy Using Pentax EMK 1000 to evaluate the presence and degree of varices.

\section{Classification of oesophageal varices was according to the} recent classification of oesophageal varices [4]:

Grade 1: Small straight varices not disappearing with insufflation.

Grade 2: Medium sized varices occupying less than one third of the lumen.

Grade 3: Large sized varices occupying more than one third of the lumen.

\section{Spleen stiffness (SSM) \& Liver stiffness (LS) measurement}

Using Fibroscan (Echosens 502) that was performed by the same operator, 10 successful acquisitions and a success rate of at least $60 \%$ was considered reliable.

\section{Interpretation of results of Fibroscan was done.}

Data collection

Data were screened, for normality assumption test and homogenecity of variance. Normality test of data using Shapiro-Wilk test was used. Additionally, testing for the homogenecity of variance revealed that there was no significant difference $(P>0.001)$.

Statistical analysis

The statistical analysis was conducted by using statistical SPSS Package program version 20 for Windows (SPSS, Inc., Chicago, IL). All statistical analyses were significant at level of probability $(\mathrm{P} \leq 0.001)$

\section{Limitation}

Technical limitations of liver elastography also apply to spleen elastography. Dedicated devices or software are required.

\section{Results}

This study included 61 liver cirrhosis patients, 38 of them were males, patients mean age was $58.28 \pm 1.18$ years. All patients had post hepatitis $\mathrm{C}$ cirrhosis, and 6 of them had history of bilharziasis in addition. 30 patients (49.20\%) were child A, 12patient (19.70\%) were child B and 19 patients $(31.10 \%)$ were child $\mathrm{C}$ with mean child score of $7.64 \pm 2.67 .14$ patients $(9.80 \%)$ had moderate ascites and 6 patients (23\%) had marked ascites by clinical examination, while by U/S there were 12 patient $(19.67 \%)$ with mild ascite,13 patient $(21.31 \%)$ had moderate ascites and 7patients (11.48\%) had marked ascites 53 patients (86.9\%) had enlarged spleen, 8 patients (13.1\%) showed average spleen with Splenic longitudinal diameter mean $(16.08 \pm 2.81) \mathrm{cm}$ by U/S, 47 patients (77\%) had shrunken liver, 12 patients (19.70.00\%) showed average liver, 2 patients $(3.30 \%)$ had enlarged liver, portal vein diameter mean was $(13.70 \pm 2.26)$ by U/S. Splenic stiffness mean was $(59.66 \pm$ $15.15) \mathrm{KPa} \&$ liver stiffness mean was $(29.46 \pm 12.11) \mathrm{KPa}$ by fibroscan.

\section{Participants were divided into three groups}

Group 1: 20 patients with liver cirrhosis and small sized oesophageal varices. (8 Child class A, 2 Child class B, 10 Child class C)

Group 2: 21 patients with liver cirrhosis and medium to large oesophageal varices. 4 patients with medium sized OV, 17 patients had large sized OV, 5 patients showed gastric varices in addition to oesophageal varices (10 Child class A, 3 Child class B, 8 Child class C)

Group 3: 20 patients with liver cirrhosis and without oesophageal varices. (12 Child class A, 7 Child class B, 1 Child class C), There was no significant difference between the three groups on comparing WBC count, hemoglobin level, AFP, T. Bilirubin results average values in each group (Table 1).

Patients who had OV (group 1) and (group had statistically significant higher INR and prothrombin concentration, lower red blood cell count and platelets count compared to patients without O.V. (group with $\mathrm{P}$ value $<0.05$. Patients who had medium and large O.V (group 2) had statistically significant lower serum albumin level and total Proteins compared to those without O.V with $\mathrm{P}$ value $<0.05$, while patients with small sized (group 1) had no statistically significant difference in serum albumin level when compared to patients without O.V (Table 2).

Splenic diameter and portal vein diameter measured by U/S were significantly higher in patients with O.V (group 1 and 2) than in patients without O.V (Table 3).

Patients with O.V in group 1 and group2 had statistically significant higher mean of spleen stiffness measured by TE compared to patients without $\mathrm{O} . \mathrm{V}$ in group 3 with $\mathrm{P}$ value 0.0001 but when comparing patients with small sized OV (group 1) with patients who had medium and large sized OV there was no statistically significant difference regarding mean of spleen stiffness.

Patients with O.V in group 1 and group 2 had statistically significant higher mean of liver stiffness measured by TE compared to patients without $\mathrm{O} . \mathrm{V}$ in group 3 with $\mathrm{p}$ value 0.0001 and when comparing patients with small sized OV (group 1) with patients who had medium and large sized OV there was also statistically significant difference regarding mean of liver stiffness with $\mathrm{P}$ value $<0.0001$ (Table 4).

Measuring liver stiffness by fibroscan as a predictor of OV has $81 \%$ and $69 \%$ sensitivity and specificity respectively while spleen stiffness assessment has $86 \%$ and $74.5 \%$ sensitivity and specificity respectively, 
Table 1. Significant comparisons between laboratory data in the studied groups.

\begin{tabular}{|c|c|c|c|c|c|}
\hline Variable & \multicolumn{2}{|c|}{ Compared Groups } & \multirow{2}{*}{$\begin{array}{c}\begin{array}{c}\text { Mean and Standard } \\
\text { Deviation }\end{array} \\
6.65 \pm 1.02 \\
\end{array}$} & \multirow{2}{*}{$\begin{array}{c}\text { P Value } \\
0.419\end{array}$} & \multirow{2}{*}{$\begin{array}{c}\text { Significance } \\
\text { NS }\end{array}$} \\
\hline \multirow{4}{*}{ Total Proteins $(6-8.3 \mathrm{Gm} / \mathrm{Dl})$} & \multirow{2}{*}{ group 1vs group3 } & group 1 & & & \\
\hline & & group3 & $6.85 \pm 0.45$ & & \\
\hline & \multirow{2}{*}{ group 2 vs group3 } & group 2 & $6.45 \pm 0.67$ & 0.034 & $\mathrm{~S}^{*}$ \\
\hline & & group3 & $6.85 \pm 0.45$ & & \\
\hline \multirow{4}{*}{ Serum Albumin $(3.5-5 \mathrm{Gm} / \mathrm{Dl})$} & \multirow{2}{*}{ group 1 vs group3 } & group 1 & $2.83 \pm 1.03$ & 0.057 & NS \\
\hline & & group3 & $3.36 \pm 0.62$ & & \\
\hline & \multirow{2}{*}{ group 2 vs group 3} & group 2 & $2.86 \pm 0.76$ & 0.032 & S* \\
\hline & & group3 & $3.36 \pm 0.62$ & & \\
\hline \multirow{4}{*}{$\begin{array}{l}\text { Prothrombin Concentration } \\
\qquad(75-140 \%)\end{array}$} & \multirow{2}{*}{ group 1 vs group3 } & group 1 & $71.1 \pm 21.34$ & 0.043 & $\mathrm{~S}^{*}$ \\
\hline & & group3 & $82.55 \pm 15.48$ & & \\
\hline & \multirow{2}{*}{ group 2 vs group 3} & group 2 & $67.86 \pm 20.32$ & 0.013 & $\mathrm{~S}$ \\
\hline & & group3 & $82.55 \pm 15.48$ & & \\
\hline \multirow{4}{*}{$\begin{array}{c}\text { International Normalizati } \\
\text { on Ratio }\end{array}$} & \multirow{2}{*}{ group 1 vs group3 } & group 1 & $1.39 \pm 0.41$ & 0.028 & $\mathrm{~S}^{*}$ \\
\hline & & group3 & $1.15 \pm 0.23$ & & \\
\hline & \multirow{2}{*}{ group 2 vs group 3} & group 2 & $1.39 \pm 0.39$ & 0.022 & $\mathrm{~S}^{*}$ \\
\hline & & group3 & $1.15 \pm 0.23$ & & \\
\hline \multirow{4}{*}{$\begin{array}{c}\text { Red Blood Cells } \\
\text { (4.7-6.1 Millions /Cc) }\end{array}$} & \multirow{2}{*}{ group 1 vs group3 } & group 1 & $4.66 \pm 1.24$ & 0.022 & $\mathrm{~S}^{*}$ \\
\hline & & group3 & $5.44 \pm 0.76$ & & \\
\hline & \multirow{2}{*}{ group 2 vs group 3} & group 2 & $4.43 \pm 0.65$ & 0.0001 & $\mathrm{~S}^{*}$ \\
\hline & & group3 & $5.44 \pm 0.76$ & & \\
\hline \multirow{4}{*}{$\begin{array}{c}\text { Platelet Count } \\
(150,000-400,000 / \mathrm{Cc})\end{array}$} & \multirow{2}{*}{ group 1 vs group3 } & group 1 & $95.55 \pm 36.63$ & 0.0001 & $\mathrm{~S}^{*}$ \\
\hline & & group3 & $152.30 \pm 37.12$ & & \\
\hline & \multirow{2}{*}{ group 2 vs group 3} & group 2 & $104.90 \pm 49.37$ & 0.001 & $\mathrm{~S}^{*}$ \\
\hline & & group3 & $152.30 \pm 37.1$ & & \\
\hline
\end{tabular}

Continuous variables are expressed as Mean \pm standard deviation (SD). P-value: probability value; S: Significant; NS: non-significant

Table 2. Significant comparison between US findings the studied groups.

\begin{tabular}{|c|c|c|c|c|c|}
\hline Variable & \multicolumn{2}{|c|}{ Compared Groups } & $\begin{array}{l}\text { Mean and Standard } \\
\text { Deviation }\end{array}$ & P Value & Significance \\
\hline \multirow{4}{*}{$\begin{array}{l}\text { Splenic Tab Diameter By U/S } \\
(10-12 \mathrm{~cm})\end{array}$} & \multirow{2}{*}{ group 1 vs group3 } & group 1 & $16.82 \pm 2.22$ & 0.018 & $\mathrm{~S}^{*}$ \\
\hline & & group3 & $14.72 \pm 2.95$ & & \\
\hline & \multirow{2}{*}{ group 2 vs group3 } & group 2 & $16.61 \pm 2.87$ & 0.048 & $\mathrm{~S}^{*}$ \\
\hline & & group3 & $14.78 \pm 2.95$ & & \\
\hline \multirow{4}{*}{$\begin{array}{l}\text { Portal Vein Diameter By U/S } \\
(7-15 \mathrm{~mm})\end{array}$} & \multirow{2}{*}{ group 1 vs group3 } & group 1 & $13.77 \pm 1.89$ & 0.023 & $\mathrm{~S}^{*}$ \\
\hline & & group3 & $12.51 \pm 1.44$ & & \\
\hline & \multirow{2}{*}{ group 2 vs group3 } & group 2 & $14.76 \pm 2.72$ & 0.002 & $\mathrm{~S}^{*}$ \\
\hline & & group3 & $12.51 \pm 1.44$ & & \\
\hline
\end{tabular}

Continuous variables are expressed as Mean \pm standard deviation (SD), P value: probability value, S: significant. Splenic diameter and portal vein diameter measured by U/S were significantly higher in patients with O.V (group 1 and 2) than in patients without O.V.

Table 3. Liver and spleen stiffness by Fibroscan

\begin{tabular}{|c|c|c|c|c|c|c|c|}
\hline Variable & Groups & & $\begin{array}{c}\text { Mean and Standard } \\
\text { Deviation }\end{array}$ & Minimum & Maximum & P Value & significance \\
\hline \multirow{6}{*}{$\begin{array}{l}\text { Spleen Stiffness } \\
(9.4-65.2 \mathrm{kPa})\end{array}$} & \multirow{2}{*}{ Group 1 Vs Group 3} & Group 1 & $65.95 \pm 9.3$ & 37 & 75 & 0.0001 & $\mathrm{~S}^{*}$ \\
\hline & & Group 3 & $41.93 \pm 8.53$ & 26.2 & 59 & & \\
\hline & \multirow{2}{*}{ Group 2 Vs Group 3} & Group 2 & $70.55 \pm 7.67$ & 45 & 75 & 0.0001 & $\mathrm{~S}^{*}$ \\
\hline & & Group 3 & $41.93 \pm 8.53$ & 26.2 & 59 & & \\
\hline & \multirow{2}{*}{ Group 1 Vs Group 2} & Group 1 & $65.95 \pm 9.3$ & 37 & 75 & 0.091 & NS \\
\hline & & Group 2 & $70.55 \pm 7.67$ & 45 & 75 & & \\
\hline \multirow{6}{*}{$\begin{array}{l}\text { Liver Stiffness } \\
(2-7 \mathrm{kPa})\end{array}$} & \multirow{2}{*}{ Group 1 Vs Group 3} & Group 1 & $28.15 \pm 6.05$ & 19 & 40 & 0.0001 & $\mathrm{~S}^{*}$ \\
\hline & & Group 3 & $17.70 \pm 4.21$ & 10 & 26 & & \\
\hline & \multirow{2}{*}{ Group 2 Vs Group 3} & Group 2 & $41.90 \pm 9.26$ & 24 & 60 & 0.0001 & $\mathrm{~S}^{*}$ \\
\hline & & Group 3 & $17.70 \pm 4.21$ & 10 & 26 & & \\
\hline & \multirow{2}{*}{ Group1 Vs Group 2} & Group 1 & $28.15 \pm 6.05$ & 19 & 40 & 0.0001 & $\mathrm{~S}^{*}$ \\
\hline & & Group 2 & $41.90 \pm 9.26$ & 24 & 60 & & \\
\hline
\end{tabular}

Continuous variables are expressed as Mean \pm standard deviation (SD). P-value: Probability Value S: Significant NS: Non-Significant 
meanwhile assessing both together is of higher sensitivity (95\%) but lower specificity (40\%) (Figure 1). Receiver operator characteristic curve (ROC) denoting the best cut off value of spleen stiffness which full fills the highest sensitivity and specificity. Overall productivity of the spleen stiffness equal to $86 \%$ at cut off level 61.25 (Figure 2). Receiver operator characteristic curve (ROC) denoting the best cut off value of liver stiffness and spleen stiffness combined which fulfil

Table 4. Sensitivity, specificity and accuracy for LS and SS

\begin{tabular}{|c|c|c|c|}
\hline Variable & Liver Stiffness & Spleen Stiffness & $\begin{array}{c}\text { Liver Stiffness and } \\
\text { Spleen Stiffness } \\
\text { Combined }\end{array}$ \\
\hline Best Cut Off & 33.5 & 61.25 & 90.5 \\
\hline Area Under Curve (AUC) & 0.748 & 0.843 & 0.963 \\
\hline Sensitivity & $81.00 \%$ & $86 \%$ & $95 \%$ \\
\hline Specificity & $69.00 \%$ & $74.50 \%$ & $40 \%$ \\
\hline Accuracy & $75.00 \%$ & $82.00 \%$ & $89 \%$ \\
\hline
\end{tabular}

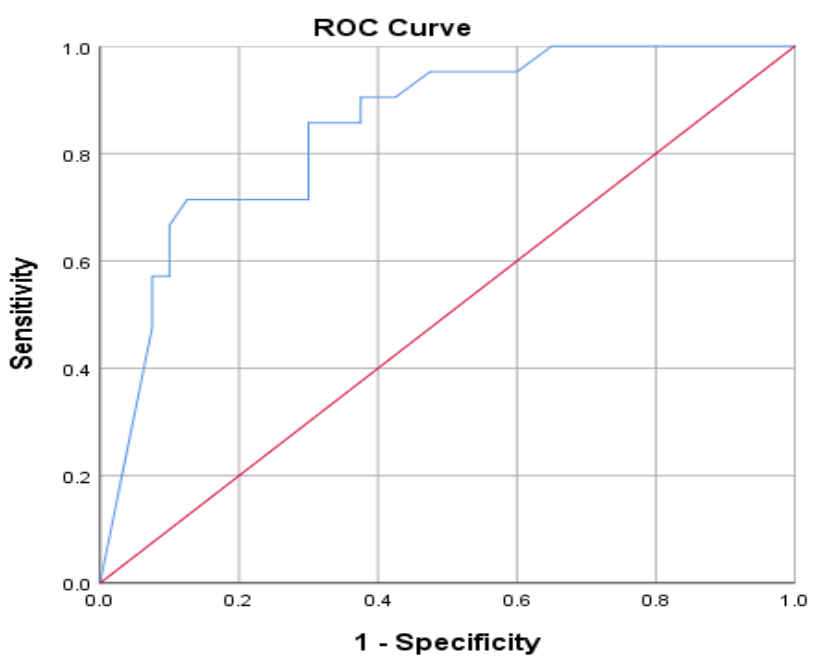

Diagonal segments are produced by ties.

Figure 1. Measuring liver stiffness by fibroscan

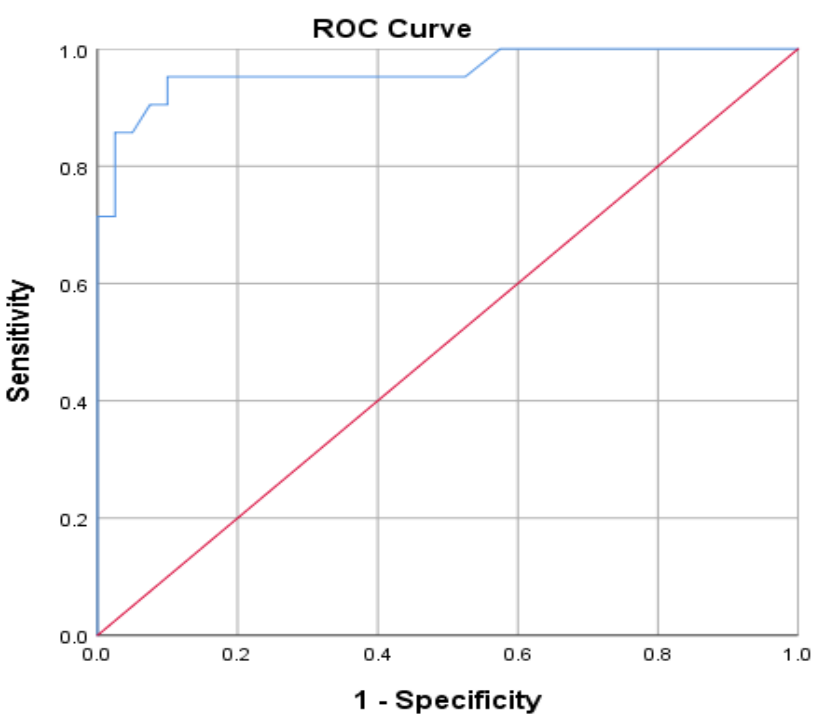

Diagonal segments are produced by ties.

Figure 2. Measuring productivity of the spleen stiffness the highest sensitivity and specificity. Overall productivity of the liver stiffness and spleen stiffness combined equals $95 \%$ at cut off level 90.50 .

\section{Discussion}

Patients with cirrhosis have high incidence of EV with high morbidity and mortality due to bleeding; active surveillance via upper gastrointestinal endoscopic examination can represent an unnecessary burden for patients, therefore, the increasing number of non-invasive tests for EV has gained wide attention. Nevertheless, few Meta analyses have involved predicting the presence or absence of $\mathrm{EV}$ and predicting the presence of large EV using Liver Stiffness value obtained with Fibroscan [5]. This study aimed to assess the diagnostic performance of Liver stiffness value measured by Fibroscan as a Transient elastography test to detect the presence of OV specially large OV in patients with liver cirrhosis and to evaluate as well the relationship between splenic stiffness and Liver stiffness measured by TE as anon invasive predictors of the presence of oesophageal varices in patients with liver cirrhosis. Our study included 61 participants with mean age $58.28 \pm 1.18,38$ male patients $(62.30 \%)$ and 23 female patients (37.70\%), who were subdivided into 3 groups. Group 1 consisted of 20 patients with liver cirrhosis and small size oesophageal varices, group 2 consisted of 21 patients with liver cirrhosis and medium to large sized oesophageal varices, group 3 consisted of 20 patients with liver cirrhosis and without oesophageal varices. All groups were matched regarding age and sex. Mean age was similar to studies done by [6].

In our study we found that Platelets count was higher in patients without oesophageal varices(group3) $\left(\right.$ Mean $\left.=152.30 \pm 37.12 \times 10^{3} / \mathrm{dl}\right)$, in comparison to patients with small sized oesophageal varices (group 1) $\left(\right.$ Mean $\left.=95.55 \pm 36.63 \times 10^{3} / \mathrm{dl}\right)$ and patients with medium and large size varices (group 2) $\left(\right.$ Mean $\left.=104.90 \pm 49.37 \times 10^{3}\right)$. These results agree with, Mantashit et al. [7] who found that the mean platelet levels were lower in cirrhotic patients with portal hypertension.

In the current study serum albumin level was statistically significant lower in patients with moderate and large varices (group 2) (Mean = $2.86 \pm 0.79 \mathrm{~g} \mathrm{dl}$ ) in comparison to patients without varices (group 3) (Mean 3.36+- $0.62 \mathrm{~g} \mathrm{dl}$ ). Our results were similar to the results of the previous studies of Leung et al. [8] who found that serum albumin level is lower in cirrhotic patients with oesophageal varices in comparison to cirrhotic patients without varices.

Our study showed that INR was prolonged in patients with O.V in group 1 with mean value $(1.39 \pm 0.41)$ and group 2 with mean value $(1.39 \pm 0.39)$ in comparison to patients without OV in group 3 with mean value $(1.15 \pm 0.23)$, this result agrees with what Kim et al. [9] found in his study, INR was higher in patient with varices than cirrhotic patients without varices. Portal vein diameter was significantly bigger in patients with medium and large varices (group2) (mean 14.60 \pm $2.68 \mathrm{~mm}$ ) and patients with small varices (group 1) (mean $13.77 \pm 1.98$ $\mathrm{mm}$ ) in comparison with patients with no varices (group 3) with mean $(12.51 \pm 1.44 \mathrm{~mm})$ in this study, what was similar to Shehata et al. [10] who found PV diameter in cirrhotic patients is a good predictor for the presence of O.V.

In current study liver stiffness measured by fibroscan in cirrhotic patients with small O.V (group1) (Mean $=28.15 \pm 6.05)$ and in cirrhotic patients with medium and large O.V (group2) $($ mean $=41.90 \pm 9.26)$ is significantly higher than that in group3 patients with liver cirrhosis and no OV (Mean $=17.70 \pm 4.21$ ), And when comparing patients with small sized OV (group 1) with patients who had medium and large sized OV (group 2) there was statistically significant difference regarding mean 
of liver stiffness as well, as it was significantly higher among patients with medium and large OV (group2), this indicates that liver stiffness measured by fibroscan can be used as a predictor of OV and its grade as well, with best cut of value $33.5 \mathrm{KPa}$, with $81 \%$ sensitivity and $69 \%$ specificity, AUC was 0.748 and $75 \%$ accuracy. Our result agrees as with El Lehleh et al. [6] who documented that measurement of liver stiffness by fibroscan is reliable for detecting presence and size of OV, so it is good test to replace Endoscopy in detecting and grading OV. Leung et al. [8] stated that Liver stiffness can be used to predict EV with cutoff value $21 \mathrm{Kpa}$ with sensitivity $78 \%$ and specificity $64 \%$.

In current study spleen stiffness measured by fibroscan in cirrhotic patients with small O.V (group1) (Mean=65.95 \pm 9.30$)$ and in cirrhotic patients with medium and large O.V (group2) (mean= $70.55 \pm 7.67$ ) is significantly higher than group 3 patients with liver cirrhosis and no OV (Mean= $41.93 \pm 8.53$ ), With best cut off value $61.25 \mathrm{KPa}, 86 \%$ sensitivity, 74.5 specificity, AUC0.843 and $82 \%$ accuracy. This result goes with Ravaioli et al. [11] cut off value of SS is $52-55 \mathrm{kPa}$ which has strong correlation with PHT \& OV. SSM for predicting EV (sensitivity $88 \%$, specificity $78 \%$ ) is superior to LSM (sensitivity $83 \%$, specificity $66 \%$ ) for predicting EV in chronic liver disease. Yet when comparing patients with small sized OV (group 1) with patients who had medium and large sized OV there was not statistical significant difference regarding mean of spleen stiffness, this indicates that spleen stiffness measured by fibroscan can be used as a predictor of OV but cannot be used to assess its grade.

Stefanescu et al. [12] study found that no significant difference could be observed between values in patients with different grades of OV, yet on comparing patients with no varices to those with oesophageal varices, regardless of grade, a strong significant difference was noted $(P$ $<0.001$ ), The SS value $>46.4 \mathrm{kPa}$ could predict the presence of O.V with a diagnostic accuracy of $81 \%$. On the contrary Ravaioli et al. [11] found that SSM has not routinely been used yet due to its technical limitation, that is, low applicability in normal-sized spleen and ceiling effect at 75 $\mathrm{kPa}$ impairing risk stratification of patients. Our result showed that Spleen stiffness is superior to Liver stiffness in predicting O.V in patients with liver cirrhosis and combination of SS and LS is better than SS and /or LS alone with sensitivity $95 \%$ and specificity $89 \%$ that agree with Karatzoas et al. [13] who stated that spleen elastography appears to be a reliable method with high negative predictive value for the presence of varices. Further evaluation, especially liver elastography, may allow the use of spleen elastography in the future as a screening test, so that EGD can be avoided in patients with negative spleen elastography.

\section{Conclusion}

- Spleen Stiffness measured by fibro scan showed acceptable diagnostic performance in predicting the presence of oesophageal varices but couldn't predict the severity (degree) of O.V. with best cut off point at $61.25 \mathrm{Kpa}$ with sensitivity of $86 \%$ and specificity of $74.5 \%$ according to our results.
- Liver Stiffness is accurate in identifying the presence or absence of oesophageal varices best cut off point for LS for prediction of oesophageal varices in liver cirrhosis patients was $33.50 \mathrm{KPa}$ with sensitivity of $81 \%$ and specificity of $69 \%$ according to our results. LS as well may suggest OV degree. So, we can reduce the need for screening endoscopy.

- Spleen stiffness and Liver stiffness measurements by fibro scan both are good non-invasive predictors for the presence of oesophageal varices in patients with chronic liver disease, using combined LS and SS may increase sensitivity to $95 \%$ while specificity will be $40 \%$.

Yet EGD remains the golden standard for the diagnosis and evaluation for the presence of $\mathrm{O} . \mathrm{V}$ in patients with chronic liver disease.

\section{References}

1. Mallet M, Rudler M, Thabut D (2017) Variceal bleeding in cirrhotic patients. Gastroenterol Rep (Oxf) 5: 185-192. [Crossref]

2. Triantos C, Kalafateli M (2014) Endoscopic treatment of esophageal varices in patients with liver cirrhosis. World J Gastroentrol 20: 13015-13026. [Crossref]

3. Zaman A, Hapke R, Flora K, Rosen HR, Benner K (2002) Factors predicting the presence of esophageal or gastric varices in patients with advanced liver disease. $A m J$ Gastroentrol 94: 3292-3296. [Crossref]

4. Philips CA, Amrish S (2016) Esophageal and gastric varices: historical aspects, classification and grading: everything in one place. Gastroentrol Rep (Oxf) 4: 186-195. [Crossref]

5. Pu K, Shi JH, Wang X, Tang Q, Wang XJ, et al. (2016) Diagnostic accuracy of transien elastography (fibroscan) in detection of esophageal varices in patients with cirrhosis, a meta-analysis. World J Gastoentrol 23: 345-356. [Crossref]

6. El Lehleh AM, El Din H Seleem H, Abdelmaksoud MM (2019) Liver stiffness measurement by fibroscan for predicting esophageal varices in patients with chronic liver diseases. Menoufia Med J 31: 594-599.

7. Mantashit W, Hrishikesh C, Samant C, Ingviya T, Esmadi M, et al. (2018) Accuracy of liver stiffness and spleen stiffness and LS-spleen diameter to platelet ratio score in detection of esophageal varices. J Gastroenterol Hepatol 33: 1696-1706. [Crossref]

8. Leung C, Loong TC, Pang J, Wei JL, Wong VW (2017) Invasive and non- invasive assessment of portal hypertension. Hepatol Int 12: S44-S55. [Crossref]

9. Kim T, Shijo H, Kokawa H, Tokumitsu H, Kubara K, et al. (2015) Risk factors for hemorrhage in gastric fundal varices. Hepatology 25: 307-312. [Crossref]

10. Shehata M, Lobna A, Khalid ES, El-Hossary M (2014) A Comparative study of doppler ultrasound and blood indices as non-invasive predictors of esophageal varices in cirrhotic patients. Tanta Med J 42: 83-91

11. Ravaioli F, Montagnani M, Lisotti A, Festi D, Mazzella G, et al. (2018) Non- invasive assessment of portal hypertension in advanced chronic liver disease: An Update. Gastroenterol Res Pract: 4202091. [Crossref]

12. Stefanescu H, Grigorescu M, Lupsor M, Maniu A, Crisan D, et al. (2011) Anew and simple algorithm for the non- invasive assessment of esophageal varices in cirrhotic patients using serum fibrosis markers and transient elastography. J Gastrointestin Liver Dis 20: 57-64. [Crossref]

13. Karatzas A, Konstantakis C, Aggeletopoulou I, Kalogeropoulou C, Thomopoulos $\mathrm{K}$, et al. (2018) Non-invasive screening for esophageal varices in patients with liver cirrhosis. Ann Gastroenterol 31: 305. [Crossref]

Copyright: (C2019 Shawky A. This is an open-access article distributed under the terms of the Creative Commons Attribution License, which permits unrestricted use, distribution, and reproduction in any medium, provided the original author and source are credited. 